Research/Technical Note

\title{
Successfully Managing the Hidden Danger of Rapid Growth: Theoretical Framework, Measurement Tools, and Practical Applications
}

\author{
Eric Flamholtz ${ }^{1, ~}$, Yvonne Randle ${ }^{2}$, Simon Kuang Yaojun ${ }^{3}$, Tony Wong Xiaohong ${ }^{3}$, Ivy Sun Qian ${ }^{3}$ \\ ${ }^{1}$ Anderson School of Management, UCLA, Los Angeles, USA \\ ${ }^{2}$ Management Systems Consulting Corporation, Los Angeles, USA \\ ${ }^{3}$ KS Consulting, Shenzhen, China
}

Email address:

eric.g.flamholtz@anderson.ucla.edu(E. Flamholtz), YR@Mgtsystems.com(Y. Randle), kuangyaojun@jzlearning.com(S.K. Yaojun), gzwangxiaohong@vip.163.com(T.W.Xiaohong),sunqian@jzlearning.com(I. S. Qian)

\section{To cite this article:}

Eric Flamholtz, Yvonne Randle, Simon Kuang Yaojun, Tony Wong Xiaohong, Ivy Sun Qian. Successfully Managing the Hidden Danger of Rapid Growth: Theoretical Framework, Measurement Tools, and Practical Applications. American Journal of Theoretical and Applied Business. Vol. 4, No. 2, 2018, pp. 48-56. doi: 10.11648/j.ajtab.20180402.13

Received: April 23, 2018; Accepted: May 31, 2018; Published: June 14, 2018

\begin{abstract}
All business organizations seek growth. Very rapid growth is celebrated as an indication of organizational success. But while growth in general, is good, too much growth too rapidly can be a very serious problem for organizations if they do not manage it appropriately. This problem is termed the "hidden dangers" of very rapid growth. Based upon decades of experience and research, this article examines how a company can identify and assess the severity of the dangers of too rapid growth. Accordingly, the article identifies the ten most common organizational growing pains; presents a method for measuring their severity and interpreting the degree of risk posed by of various "levels" (numerical scores) of growing pains; examines a case example of a company dealing with growing pains; and proposes some practical actions steps to reduce growing pains and their related risks (danger). The article proposes that the optimal strategy for a firm that anticipates rapid growth is to build an infrastructure sufficient for the size of the organization it anticipates becoming prior to actually reaching that size.
\end{abstract}

Keywords: Rapid Growth Growing Pains, Hidden Dangers, Infrastructure

\section{Introduction}

All business organizations seek growth. Very rapid growth is celebrated as an indication of organizational success. But while growth in general, is good, too much growth too rapidly can be a very serious problem for organizations if they do not manage it appropriately.

\section{The Hidden Danger of Very Rapid Growth}

Growth, while essential to all forms of life, can be a mixed blessing. It indicates an organism's success in meeting the challenges posed by its environment; but growth also signals a need for new strategies appropriate to the often very different creature the organism has become. If these new strategies are not developed adequately, the organism may find itself overwhelmed by its own growth which, if left unchecked, may lead to its own demise. Examples of this are many: Cells which grow too rapidly are "cancerous," and can eventually destroy the host organism on which their lives depend; human organizations which grow too large experience chaos in their operations, lose coordination, and eventually may fail.

Even though organizations are themselves inanimate, organizational growth is not different than growth in other forms of life. Growth in revenues indicates an organization's success in meeting the challenges posed by its environment; but growth also signals a need for new strategies appropriate to the often very different creature the organization has become. For example, Tesla is clearly an example of a successful organization in terms of growth. Tesla has become the current leader in sales of electric automatable. Tesla's market value has grown at an astonishing rate. 
Nevertheless, even mighty Tesla is not immune to the dangers of too rapid growth. Specifically, some problems are being reported by "Model 3" owners, as discussed in article in the Los Angeles Times was entitled "Tesla's Troubles [1]." The article referred these problems as "Tesla's 'Growing Pains [2]'". Elon Musk exhibits qualities of true genius. We view him as the ultimate visionary and would truly love to see him succeed! However, he is playing a very dangerous game. Musk and Tesla need to understand the consequences of growing pains and take appropriate organizational development actions.

The problems of the danger of too rapid growth are not just a problem for US companies; it is a global phenomenon. For example, companies in China, both large and small, are also not immune to the problems and dangers of too rapid growth. Accordingly, companies experiencing very rapid growth must identify and assess the severity of the dangers of their own rapid growth.

This article deals with the critical issue of successfully managing rapid growth. It presents a theoretical framework to explain the concealed dangers of rapid growth, presents measurement tools to assess the degree of severity of the classic problems which typically accompany rapid growth, and also presents a study of an application of the theory and measurement methods in an actual organization in China, a nation where rapid growth accompanied by hidden dangers is a widespread but largely unrecognized phenomenon. Specifically, this article will:

1) identify the ten most common organizational growing pains;

2) present a method for measuring their severity and interpreting the degree of risk posed by of various "levels" (numerical scores) of growing pains;

3) examine a case example of a company dealing with growing pains; and

4) Propose some actions steps to reduce growing pains and their related risks (danger).

\section{The Hidden Danger of Very Rapid Growth}

When an organization has not been successful in developing the infrastructure or management systems it needs at a given stage of growth, it begins to experience some classic problems. These problems are indications that something has gone wrong in the process of organizational development, and an "early warning" of significant future problems. These problems are called "growing pains, because they are caused by rapid growth that is not accompanies by the sufficient development of organizational infrastructure.

\section{The Ten Most Common Organizational Growing Pains} [3]:

The ten most common organizational "growing pains" are
1) People feel that "there are not enough hours in the day."

2) People are spending too much time "putting out fires."

3) People are not aware of what others are doing.

4) People lack an understanding about where the firm is headed.

5) There are too few good managers.

6) People feel that, "I have to do it myself if I want it done correctly."

7) Most people feel that meetings are a waste of time.

8) When plans are made, there is very little follow-up, so things just don't get done.

9) Some people have begun to feel insecure about their place in the firm.

10) The firm has continued to grow in sales, but not in profits.

\subsection{People Feel That There Are Not Enough Hours in the Day}

People feel they can work 24 hours a day and still not get all the required work done. Employees' belief that they are being endlessly overworked may bring on morale problems. They may simply decide they can no longer operate under these conditions and may leave the organization. This will result in significant turnover costs and replacement costs related to recruiting, selecting, and training new people.

\subsection{People Spend too Much Time "Putting Out Fires"}

Examples of "putting out fires" problem are easy to find. "Fires" or crises were so prevalent at one $\$ 50$ million manufacturing company that managers began to refer to themselves as "fire fighters," and senior management rewarded middle management for their skills in handling crisis When it became apparent that managers who had been effective in "fire prevention" were being ignored, some of them became "arsonists" to get senior management's attention.

\subsection{People Are Not Aware of What Other People Are Doing}

This creates a situation in which people and department do whatever they want to do and say that the remaining tasks are "not our responsibility." Constant bickering between people over responsibility for things not getting done may ensue.

\subsection{People Lack Understanding About Where the Firm IS Headed}

Employees may complain that "the company has no clear direction." When insufficient communication is combined with rapid changes, employees may begin to feel anxious. If anxiety increases to the point where it becomes unbearable, employees may begin leaving the firm. It should be noted that turnover of this kind can be very costly to the firm.

\subsection{There Are too Few Good Managers}

Although the firm may have people who hold the title of "manager", it may not have good managers. Rapid growth at 
Apple computer led Steven Jobs to bring in "professional managers" to help manage the firm because the company had not developed a cadre of managers as it grew. However, this led to the inevitable culture clash. I must be noted that this growing pain is generally among the top five in companies globally. However, in China it is virtually always no. 1 or no. 2 [4].

\subsection{People Feel That “I Have to Do It Myself to Get It Done Correctly"}

Increasingly, as people become frustrated by the difficulty of getting things done in an organization, they come to feel that "if I want to get something done correctly, I have to do it myself." Operating under this philosophy, departments become isolated from one another and teamwork becomes minimal.

\subsection{Most People Feel the Meetings Are a Waste of Time}

Unfortunately, at many organizations, meetings have typically no planned agendas, and often they have no designated leader. As a consequence, the meetings become a "free-for-all," tend to drag on interminably, and seldom result in decisions.

Other complaints about meetings involve lack of follow up on decisions that are made. Meetings are also ineffective if people ignore the goals that have been set or fail to monitor their progress toward these goals.

\subsection{When Plans Are Made, There Is Very Little Follow-Up so Things Just Don't Get Done}

Recognizing that the need for planning is greater than in the past, an entrepreneur may introduce a planning process. People go through the motions of preparing business plans, but the things that were planned just don't get done. In some cases, there is no follow-up because the company has not yet developed systems adequate to monitor its goals. In other cases, follow-up does not occur because personnel have not received proper training in setting, monitoring, and evaluating goals.

\subsection{Some People Feel Insecure About Their Place in the Firm}

Typically the entrepreneur has become anxious about problems facing the organization and has therefore hired a "heavy-weight" manager from outside. This action may have been accompanied by the termination of one or more current managers. Employees begin to wonder if whether they will be the next to "get the axe." The term "get the axe" is an idiomatic expression referring to people's employment being terminated. In an attempt to protect them, they keep their activities secret and do not "make waves." This results in isolation as well as a decrease in teamwork. When anxiety becomes too high, it may result in morale problems, turnover, or a very political environment.

\subsection{The Organization Continues to Grow in Sales But Not}

\section{in Profits}

If all the other growing pains are permitted to exist, this final symptom can emerge. In some instances, sales continue to increase while profits remain flat, so that the company is succeeding in only increasing its workload. In the worst cases, sales increase while overall profits decline.

\section{Nature and Causes of Organizational Growing Pains}

Growth, though essential to organizations over the long term, creates its own set of problems: the growing pains described above. These growing pains are symptoms that something has gone wrong in the growth and development of a business enterprise. They are "symptoms" of organizational distress, and, as shown in our published empirical research, an early warning or leading indicator of future organizational difficulties, including financial difficulties $[3,5]$.

Growing pains indicate that the "infrastructure" of an enterprise (i.e., the resources, internal operational and management systems and culture it needs at a given stage of growth) has not kept up with its size, as measured by its revenues. Stated differently, it means that scale-up has not been successful. For example, a business with $\$ 200$ million (U.S.) in revenues may only have an infrastructure to support the operations of a firm with $\$ 50$ million in revenues, or one-fourth its size. This type of situation typically occurs after a period of growth, sometimes quite rapid growth, where the infrastructure has not been changed to adjust to the new size and complexity of the organization. The result (as shown graphically below) is an "organizational development gap," (that is, a gap between the organization's actual infrastructure and that required at its current size or stage of development) which produces the growing pains.

\section{Measuring Organizational Growing Pains}

Growing pains are not just binary, meaning they exist or not. There are degrees of severity of growing pains. The severity with which an organization experiences these growing pains indicates the extent to which it is experiencing problems scaling up (to the next stage of development). When these Growing Pains are extreme, the organization is in jeopardy of failing if it does not take the steps needed to develop the systems, processes, and design needed to take it fully into the next stage of growth (i.e., have a design that "fits" with its size).

To assist the management of an entrepreneurial company in measuring the organization's growing pains, we have developed the Survey of Organizational Growing Pains. This survey is available on our firm's web site and can be completed free of cost: www.Mgtsystems.com.

This survey instrument presents the ten organizational growing pains cited above. Responses to the survey are 
entered on a Likert-type five-point scale, with descriptions ranging from "to a very great extent" to "to a very slight extent. By placing check marks in the appropriate columns, the respondent indicates the extent to which he or she feels each of the ten growing pains characterizes the company.

\subsection{Scoring the Survey}

Once the survey has been completed, the total represents the organization's growing pains score. It can range from 10 , which is the lowest possible or most favorable score, to 50, which is the highest possible or most unfavorable score.

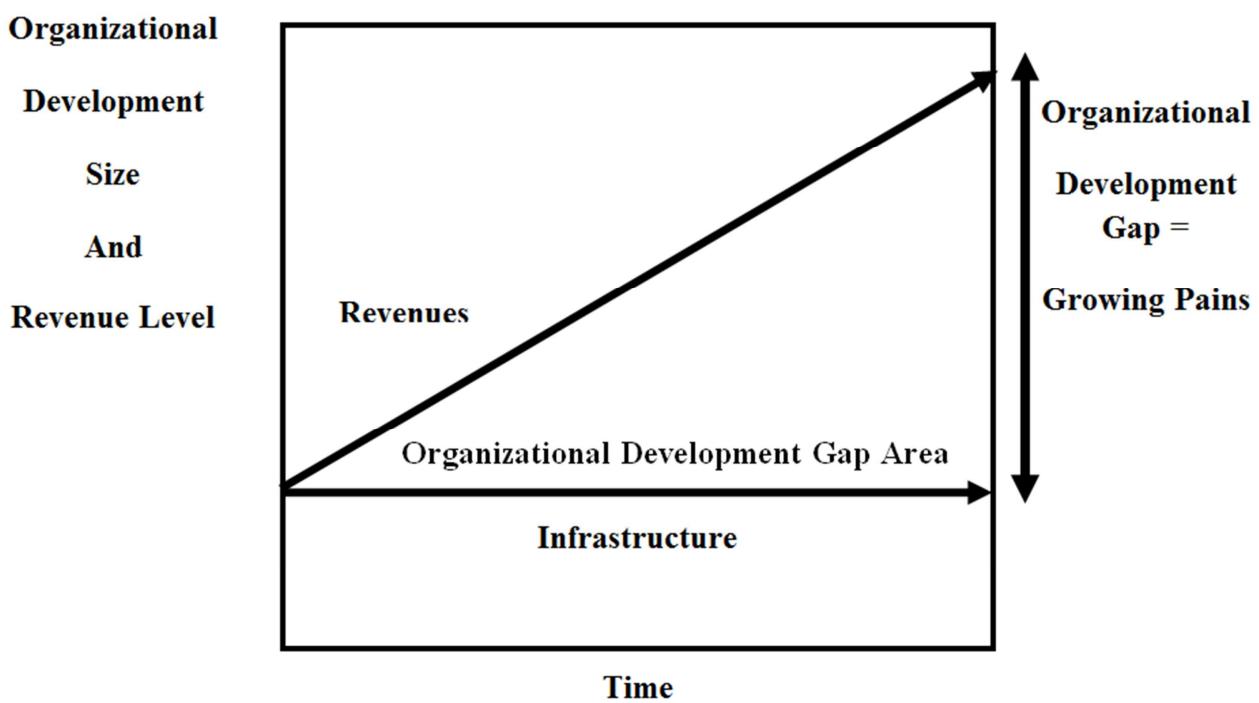

Figure 1. Organizational development gap \& growing pains.

\subsection{Interpreting the Survey Scores}

Previous research has led to the development of a validated method for measuring the degree of severity of growing pains as well as the level of risk associated with different levels of growing pains, as summarized below $[3,5]$.

The degree of seriousness of problems indicated by different growing pains scores is indicated by the color-coding scheme shown below in Table 1. This table shows five different levels of severity of growing pains from a very health organization to one that is at grave risk of failure.

Table 1. Interpretation of Organizational Growing Pains Survey Scores.

\begin{tabular}{llll}
\hline Levels & $\begin{array}{l}\text { Score } \\
\text { Range }\end{array}$ & Color & Interpretation \\
\hline 1$)$ & $10-14$ & Green & Everything OK \\
$2)$ & $15-19$ & Yellow & Some things to watch \\
$3)$ & $20-29$ & Orange & Some areas that need attention \\
$4)$ & $30-39$ & Red & $\begin{array}{l}\text { Some very significant problems } \\
\text { A potential crisis or turnaround } \\
\text { situation }\end{array}$ \\
\hline
\end{tabular}

A more detailed interpretation of score ranges is as follows:

A green score represents a fairly healthy organization. It suggests that everything is probably functioning in a manner satisfactory for the organization at its current stage of development.

A yellow score indicates that the organization is basically healthy, but there are some areas of concern. It is like hearing from your doctor, "Your cholesterol is in the normal range but on the high side. It's something to watch and be careful about but not an immediate concern."

An orange score indicates that some organizational problems require attention and action. They may not be too serious yet, but corrective action should be taken before they become so.

$A$ red score is a clear warning of present or impending problems. Immediate corrective action is required.

A purple score indicates that the organization is having very serious problems and is in crisis. The organization is in distress and may be on the verge of collapse. There may not be enough time to save it.

\subsection{Survey Scores Requiring Analysis and or Action}

If a firm's score exceeds 20, a more in-depth analysis to identify problems and develop recommendations for future action is warranted. Such a score may be a signal that the firm has reached a new stage in its development and must make major, qualitative changes. Failure to pay attention to a score of this magnitude can produce very serious dysfunctional results, including the risk of organizational failure.

\section{Empirical Research Supporting This Framework}

There is a growing body of empirical evidence which provides support for the proposed framework described above $[3,5]$. Specifically, Flamholtz and Aksehirli [6] empirically tested the proposed link between the organizational development model and the financial success of organizations. They analyzed financial and non-financial information relevant to the hypothesized model for eight pairs of companies in different industries, and found a statistically significant relationship.

Flamholtz and Hua [7] provided additional empirical 
evidence of the hypothesized link between the organizational development model and financial performance. They reported the results of a test within a single firm, using a set of fifteen relatively comparable divisions, and found a statistically significant relationship. They also identified thresholds of strategic organizational development for profitability of individual companies or operating units.

Flamholtz [8] provided empirical evidence of the hypothesized link between corporate culture and financial performance. He reported a test of this relationship within a single firm, using a set of 18 comparable divisions. He found a statistically significant relationship between culture and financial performance.

Flamholtz and Kurland [9] have replicated the study by Flamholtz and Hua [7]. The prior research was replicated with similar results in an independent research site in a different industry (financial services). Using a set of seven relatively comparable divisions, Flamholtz and Kurland [8] reported the results of a test within a single firm. They found a statistically significant relationship between the six key variables contained in the pyramid and financial performance. They also found that a statistically significant relationship between the variables that are hypothesized to comprise an organization's infrastructure and financial performance. The variables comprising infrastructure include; resources, operational systems, management systems, and culture.

\section{Applying the Framework: The Dangers of Very Rapid Growth at "Silicon Dragon"}

Previous sections have identified the ten most common organizational growing pains, discussed their causes, and presented a method for measuring their severity and interpreting the degree of risk posed by of various "levels" (numerical scores) of growing pains. This section examines a case example of a company dealing with growing pains, and shows how the company engaged in an organizational development program with specific actions steps to reduce their growing pains and their related risks (danger). The company used in this illustration is Silicon Dragon. It should be noted that although the company is from China, this same phenomenon of the dangers of rapid growth has been observed in many countries throughout the world, including Argentina, Australia, Bulgaria, Canada, Indonesia, Israel, Hong Kong, Italy, Kazakhstan, Malaysia, Mexico, Philippines, Poland, Russia, Singapore, Switzerland, Ukraine, USA and Vietnam [3].

\subsection{Description and History of Silicon Dragon}

"Silicon Dragon" is a designer and manufacturer of highly specialized custom chips for a wide variety of business, including telecommunications, information processing, artificial intelligence, and "The Internet of Things." The company is located in Shenzhen, China.

In contrast to the large Chip manufacturers, Silicon Dragon does not produce mass chips. It is part of the growing number of companies that develop intellectual property "blue prints" and license them to others to manufactories of chips and even end product manufacturers. However, it does have a small facility for manufacturing custom chips in low volumes.

Qing Li, also (known as "Tony") the founder of, Silicon Dragon, began his career as a salesman for a major telecommunications and information products design and manufacturing firm. Tony worked hard to learn all he could about the industry, and discovered that the company for which he was working was not adequately meeting all of its customers' needs. Specifically, there was an untapped market for highly specialized custom products. The market was small by the standards of the large firms like Huawei or Samsung; but for a small manufacturer it was a potentially profitable niche.

So, in 2007, he decided to start his own company. Apparently Tony's belief about the demand for his products was accurate, because within a few years his firm began to experience rapid growth. By the beginning of 2015, the company had reached more than $\$ 20$ million in annual revenues, and it was estimated that by 2020 it would achieve $\$ 50$ million in yearly revenues. Silicon Dragon personnel increased from 25 in 2007 to 200 in 2015.

\subsection{The Onset of Growing Pains}

As early as 2010, Silicon Dragon was beginning to experience certain organizational problems, symptoms of growing pains. Some symptoms were more serious than others, but they all signaled that there were some deeper problems which eventually could lead to Silicon Dragon's failure. These symptoms are described below.

\subsubsection{Many People Were Not Aware of What Others Were Doing}

A significant number of people did not understand what their jobs were, what others' jobs were, or what the relationships were between their jobs and the jobs of others. This problem resulted, in part, from a tendency to add personnel without developing formal descriptions of roles and responsibilities. Since employees were added on an ad hoc basis whenever a staff shortage seemed imminent, there was often little time to orient them to the organization's operations or to train them adequately in what their own responsibilities would be. Indeed, there was no formal training program.

Some people were given job descriptions, but did not adhere to their specified roles. Others were given a title, but no explicit responsibilities. Surprisingly, many individuals often did not know to whom they were to report, and managers did not know for which employees and activities they would be held accountable. People learned what they were supposed to do on a daily basis; long-range planning was non-existent.

Interactions between departments were also a problem. Managers often did not understand what their responsibilities were and how what they were doing fit in with the firm's overall operations. New departments were created to meet's product and marketing needs, but many managers were not 
aware of how these departments fit in with the rest of the organization. One manager complained, "People sit outside my door, but I don't even know what they do." Another new manager described his introduction to Silicon Dragon as follows: "I was walked to an area and told: 'This is your department. Run it.'

This lack of formal roles and responsibilities made it easy for personnel to avoid responsibility whenever a task was not completed or was completed unsatisfactorily. This also led to duplication of effort between departments. Since no one knew precisely whose responsibility a particular task was, two or more departments or people often would complete a task, only to find that it had already been accomplished by someone else.

\subsubsection{People Felt There Were Not Enough Hours in the Day}

Most employees felt "overloaded." They commonly stayed after hours to complete their work. Departmental managers, in particular, felt that their workload was too great and that deadlines were unrealistic.

This situation resulted, in part, from the lack of adequately developed operational systems to support Silicon Dragon employees' work. The accounting, operational planning, and communication systems were adequate for a small company, but quite inadequate for one as large as Silicon Dragon had become. Systems for purchasing, inventory control, and even mail distribution were either poorly developed or nonexistent.

\subsubsection{People Spent too Much Time "Putting Out Fires"}

Perhaps the best indication that Silicon Dragon was beginning to choke on its growth was that employees spent an increasing amount of time dealing with short-term problems resulting from the lack of long-range planning. This was particularly evident in the constant lack of space within the company's headquarters. It appeared to most employees that as soon as the company increased its office space, the space already was filled, and it was time to begin planning for another move. It seemed that there was never enough space or equipment to support the company's staff adequately. Salespeople, when they worked at the firm's headquarters, usually arrived early to ensure they would be able to find a vacant desk from which to make their calls. Employees who did not go out into the field attempted to handle the cramped space by creating "schedules" for using phones, computer terminals, and even desks. Employees began to feel that Silicon Dragon never planned, it simply reacted. (An informal joke around the company was: "At Silicon Dragon, long-range planning means 'what I am going to do after lunch'.") This was caused partly by the changes in the marketplace and the new demands placed upon the company. It also resulted from the tendency of entrepreneurial companies like Silicon Dragon to spend most of their time simply staying afloat without keeping an eye on the future.

Employees began to think that because "crisis is the norm" at the company, this is the way they should operate. They began to call themselves "the fire fighters," and even took pride in their ability to deal with crises.

\subsubsection{There Were Not Enough Good Managers}

Most managers at Silicon Dragon were promoted to their positions in recognition of service. Some were good managers, but most were described by their subordinates as "good technicians who lack people skills." Further, they were seen as clones: Many employees believed that management had one and only one way of doing things and that to deviate from the norm would result in adverse consequences.

Many people had the title "manager," but relatively few really behaved as managers. After promotion, many people simply kept doing the things they had done in their former roles. They were poor delegators, often doing the work themselves rather than assigning it to others. As a result, employees came to believe that their managers did not trust them.

Tony was a strong individual who wanted things done his way, and he wanted to control almost everything. Tony recognized this, referring to himself as "someone who sticks his nose into everything." Few decisions were made without Tony's approval or review. As a consequence, one of two things tended to happen concerning managers: 1) The stronger managers tended to "butt heads" with Tony and ultimately left; and 2) The remaining managers were slowly turned into "managerial eunuchs." Those managers who decided not to leave Silicon Dragon tended not to take Tony on, at least directly, and they had little real authority and certainly no power. Inadvertently, Tony had created an organization of weak people or what has been termed "managerial pygmies." In effect, he was a victim of his own need for control. This phenomenon is part of what has been termed "the entrepreneur's syndrome. For a detailed discussion of this syndrome, see Eric Flamholtz and Yvonne Randle [10].

When business plans were made, there was very little follow-up, and things didn't get done. As is true of many small and growing firms, Silicon Dragon had traditionally operated on an ad hoc basis. No formal strategic planning system was needed, since Tony had provided all of the firm's direction. Further, the informal structure had allowed Silicon Dragon employees the freedom to generate new product and marketing ideas.

As the company grew, however, Tony and his senior management team began to realize the firm needed to monitor its operations. Unfortunately, Silicon Dragon had not developed the systems necessary to have accountability.

\subsubsection{There Was a Lack of Understanding About Where the Firm Was Going}

Many Silicon Dragon employees complained that not only did they not know what was expected of them; they could not understand where the company was headed in the long term. This resulted from the inability of Silicon Dragon management to communicate its vision for the future to the company's personnel. Employees were aware that changes were being made, but were not always sure how these changes would affect them or their departments. Consequently, many employees experienced high levels of anxiety. When this anxiety became too great, many left the firm. 


\subsubsection{Most People Felt Meetings Were a Waste of Time}

Employees complained that too many meetings were held among top managers and not enough among the lower levels of the organization. In addition, those meetings that were held were often inefficient and did not result in resolutions to problems. This was because few meetings had written agendas or minutes - many of those attending described them as "free-for-alls." They were at best discussions, and at worst fights between departments or individuals. Worst of all, they went on interminably.

Moreover, people complained that most meetings were called on an ad hoc basis. Since these meetings were unscheduled, people typically came to them without any sense of their purpose and certainly with no preparation. Thus, they tended to have the atmosphere of "bull sessions" in which people shot from the hip. In addition, people felt that they could not plan their work because they were constantly interrupted for "crisis" meetings.

Some people began to feel insecure about their places at the firm. This problem grew out of the many changes taking place and the large number of problems the firm was encountering as it grew. Some original "founding members" were terminated and replaced. This caused people to wonder who was next. Although many recognized that some employees had not grown as the company grew, they worried about their jobs and their places within the firm. This, in tum, led people to spend an increasing amount of their time "covering their vested interests."

\subsubsection{The Company Grew in Sales But Not in Profits}

Silicon Dragon, like many entrepreneurial firms, traditionally had been most concerned with increasing sales. It adopted the philosophy of many growing firms: "If we're selling more, we must be making more profits." Unfortunately, this is not often the case. The other side of the profit equation, costs, often increases along with sales, and if costs are not contained, the firm soon may find itself in a position of losing, rather than making, money. Thus, although Silicon Dragon sales were increasing at a rapid rate, profits were remaining relatively constant.

Silicon Dragon's problems certainly are not unique. Indeed, they are the classic symptoms of organizational growing pains. It should be noted that while these "symptoms" represent problems in and of themselves, they also suggest a deeper, more systemic organizational problem. Specifically, they signal that the organization is coming precariously close to choking on its own growth. This, in tum, indicates that the organization must change its very nature; it must make a transition to a different kind of organization, with a more developed managerial abilities and systems.

\subsection{The Need for Organizational Development}

During 2015, Qing Li recognized that Silicon Dragon, the company to which he had devoted a great deal of his time, energy and money, was experiencing serious problems. He engaged an experienced organizational development consultant to assist him. The consultants proposed a four step program to help Silicon Dragon develop the organizational capabilities required at its current size and stage of growth and, in turn, overcome the problems associated with growth.

The four specific steps in the program were as follows.

Phase 1: Assess the company's current state of development as an organization and its future development needs.

Phase 2: Design a program for the development of the organization as a whole.

Phase 3: Implement the organizational development program.

Phase 4: Monitor the program and make changes as needed.

\subsection{Organizational Development at Silicon Dragon: Phase 1}

An organizational assessment was performed to assess Silicon Dragon's current state of development and future needs. The assessment involved collecting information from employees about their perceptions of Silicon Dragon and its operations. One tool used in this process was the "Symptoms of Organizational Growing Pains Questionnaire." This survey instrument measures the extent to which an organization is experiencing the ten classic symptoms of growing pains and is in danger of "choking on its own growth." For more information about this survey, see www.Mgtsystems.com.

The scores on this questionnaire for silicon Dragon ranged from 30 to 34, with an average score of 32. This indicated that the company was experiencing some very significant problems (see Exhibit 2), which required immediate attention. Specifically, the audit revealed that the company needed to:

1) Better define organizational roles and responsibilities and linkages between roles;

2) Help employees plan and budget their time;

3) Develop a long-range business plan and a system for monitoring it;

4) Increase the number of qualified present and potential managers;

5) Identify the direction the company should take in the future;

6) Reduce employee and departmental feelings that they always "need to do it themselves" if a job is to get done;

7) Make meetings more efficient by developing written agendas and taking and distributing meeting minutes; and

8) Become profit-oriented rather than strictly sales-oriented.

All of these needs were an outgrowth of an underdeveloped organizational infrastructure at Silicon Dragon.

\subsection{Organizational Development at Silicon Dragon: Phases 2}

Having identified its organizational problems and developmental needs, Silicon Dragon proceeded to the next step: designing and implementing a program that would resolve problems and help the company develop the infrastructure necessary to accommodate its rapid growth. Management met at a retreat to design a plan for the firm. The plan included specific objectives in key organizational 
development areas.

After the plan was established, the organization met monthly to review the plan and the performance achieved. It also formulated specific action steps to overcome its problems.

Some of these steps were: 1) implementation of a strategic plan which defined the company's business, mission, key result areas, goals, and action plans; 2) design of a management-development program to help people become better managers and overcome the "doer syndrome"; 3) recruitment of new professionals with the advanced skills needed to guide the firm; 4) development of a formal set of job descriptions and a performance appraisal system.

\subsubsection{Implementing Strategic Planning}

One of the first steps Silicon Dragon took to manage its growth was to begin developing a strategic plan. The major goal of this process was to motivate the company's managers to begin to take a longer-range view than "what's happening after lunch." A related goal was to affect the corporate culture at Silicon Dragon and make planning a way of life.

The process began with a two-day strategic planning retreat which focused on some fundamental issues necessary to guide the future development of the company, including:

1) What business is Silicon Dragon in?

2) What are our competitive strengths and limitations?

3) Do we have a market niche?

4) What are the key factors responsible for our past success, and to what extent will they be account able for our future requirements for' success?

5) What should our objectives be for developing Silicon Dragon as an organization?

6) What should our action plans be, and who is responsible for each action plan to implement our specific objectives?

In addition to these core strategic planning issues, which are relevant to all organizations, the company also examined certain specific strategic issues peculiar to its operations.

After the strategic planning retreat, a draft of a corporate strategic plan was prepared. This plan specified the firm's business definition, mission, key result areas, objectives and goals, and action plans. The plan was circulated among the firm's senior managers for their comments and input. It was revised and approved by Fletcher, and then distributed to all senior managers. The plan provided a "blueprint" for future development, including specific objectives focused upon eliminating the problems leading to the company's growing pains.

Silicon Dragon then held quarterly meetings to review the company's results, compare them with the plan, and make required adjustments. This signaled that the plan was more than merely a "paper plan"-it was a real management tool.

A key decision by management was to be more selective in accepting new business until the firm had digested its present growth by building the required infrastructure.

\subsubsection{Management Development}

Qing Li and Silicon Dragon's other senior managers realized that people were Silicon Dragon's true asset. The firm's technology, products, and equipment were really al the output of its people - and, therefore, the true differentiating factor was the motivation and skills of its people.

Recognizing this, Silicon Dragon believed the company had to make an investment in building its managerial capabilities for two reasons. First, there simply were not a sufficient number of effective managers. Although many people had managerial titles and could recite the right "buzzwords," relatively few were really behaving as managers. They were spending too much time as doers rather than managers; there was little time delegation; and insufficient effort was given to planning, organizing people, performance appraisal, and control, which are the essence of management. Another need for management development was more symbolic. Tony $\mathrm{Li}$ recognized that some of the people who had helped build Silicon Dragon to its current size were in jeopardy of becoming victims of "The Peter Principle": that is, they had been promoted to their level of incompetence. Tony felt that the company owed its people a chance to grow with it, and he saw management development as a chance to provide them the opportunity. Quite frankly, he felt that if people had this opportunity and failed to grow, the firm could feel it had met its responsibilities to them.

To deal with these issues, Silicon Dragon asked his consultant to design a management development program for its personnel. Two programs were developed: one for top managers and one for middle managers.

\subsubsection{Recruitment of New Professionals}

As the company grew, so did its need for greater skills and sophistication in certain functional areas. A controller was recruited to replace the firm's bookkeeper. A national sales manager was appointed. Silicon Dragon also hired a personnel director and a marketing manager. Moreover, the firm engaged a consultant to serve as its "adjunct" management development and organizational development advisor. In brief, the firm made a significant investment in its human resources. These people, in turn, were responsible for developing the operational systems required to manage growth in various areas.

The fourth major step in strengthening Silicon Dragon $\mathrm{s}$ infrastructure was to develop operational systems. The most significant of these were systems for job descriptions and performance appraisals.

\subsection{Organizational Development Results at Silicon Dragon}

For 18 months, Silicon Dragon implemented its new program of organizational development. After this period, the survey of Growing pains was re-administered. Silicon Dragon's organizational growing pain scores had decreased from an average score of 32, which put the company in a "red flag" danger zone, to a score of 23 , which indicated some problems but nothing of major concern. This improvement occurred despite the fact that the firm continued to grow. Moreover, the firm's profitability increased significantly during this period, as a wide variety of operational inefficiencies were eliminated. 
In brief, Silicon Dragon had made a fundamental transformation. Under the leadership of Qing "Tony" Li, Silicon Dragon had gone from a firm about to choke on its own growth to one that was able to absorb growth and operate profitably and effectively.

We hope that this case study will provide a useful perspective, insights, and lessons for companies facing problems similar to Silicon Dragon's. Other similar cases (but in US Organizations) can be found in $[11,12]$.

\section{Conclusion: The Final Lesson}

When an organization's growth outstrips its infrastructure, organizational growing pains such as those described above will result. If the underlying cause of those organizational growing pains is not corrected, the organization might begin to experience great difficulty.

It is extremely difficult for firms to deal with very high growth (referred to as "hyper growth") for more than two or three years without finding emerging growing pains. When this happens, a firm can become dangerously close to "choking on its own growth." For example, Osborne Computers, a pioneer in the portable personal computers business, achieved $\$ 100$ million in revenues after being in business for only two years, but went into bankruptcy in year three! Tesla, a pioneer in electric cars, is, as discussed previously, experiencing severe growing pains.

The optimal strategy for a firm that anticipates rapid growth is to build an infrastructure sufficient for the size of the organization it anticipates becoming prior to actually reaching that size. This strategy of building the infrastructure prior to actual growth is not merely appropriate for large companies, but for relatively small entrepreneurships as well. The power of this strategy of "building infrastructure in advance of need" is clearly illustrated by the vastly different experience of Osborne Computers and Compaq Computers. Osborne Computers was one of the first to market portable PCs and rapidly reached $\$ 100$ million in revenues, but it soon imploded. In contrast, Compaq delayed their market entry by more than a year (and thereby sacrificed the so-called "first mover advantage") in order to create the infrastructure to support becoming a multibillion organization. Osborne grew very rapidly with an inadequate infrastructure. It seemed (on the surface) to be successful, but it experienced severe growing pains and failed. In contrast, Compaq which built its infrastructure in advance of its actual need ultimately reached more than $\$ 40$ billion in revenues before being acquired by Hewlett-Packard.

\section{Conclusion: Implications for Action}

Returning to our example of Tesla cite above, Elon Musk exhibits qualities of true genius. We view him as the ultimate visionary and would truly love to see him succeed! However, he is playing a very dangerous game. Musk and Tesla need to understand the consequences of growing pains and take appropriate organizational development actions.

Organizational leaders like Elon Musk and Qing Li must learn how to manage growth and the inevitable transformations it requires. Specifically, leaders of organizations of any size must learn to recognize organizational growing pains and take steps to alleviate them so that their organizations can continue to operate successfully over the long term. This is the ultimate lesson (and benefit) of the theoretical framework, measurement methods, and illustrative application presented in this article.

\section{References}

[1] Mitchell, R. "Tesla's Troubles," Los Angeles Times. Business, pp. 1 and 7, February 18, 2018.

[2] M Mitchell, R. "Tesla's Troubles," Los Angeles Times. Business, pp. 1 and 7, February 18, 2018itchell, R. "Tesla's Troubles," Los Angeles Times. Business, pp. 1 and 7, February $18,2018$.

[3] Flamholtz, E. and Y. Randle, Growing Pains: Building Sustainably Successful Organizations, Wiley 2016.

[4] Source: Management Systems growing pains data base, unpublished. 1980 to present.

[5] Flamholtz, E. G. (2002-03) "Towards an Integrative Theory of Organizational Success and Failure: Previous Research and Future issues," International Journal of Entrepreneurship Education, Vol. 1, Issue 3, pp. 297-319.

[6] Flamholtz, Eric G. and Z. Aksehirli, (2000) Organizational Success and Failure, an Empirical Test of a Holistic Model, European Management Journal, 18, (5) 488-498.

[7] Flamholtz, E. and Hua, Wei, (2002). Strategic Organizational Development and the Bottom Line: Further Empirical Evidence, European Management Journal, 20 (1), 72-81.

[8] Flamholtz, E. (2001). "Corporate Culture and the Bottom Line," European Management Journal, 19 (3), 268-275.

[9] Flamholtz, E and Kurland, S. Strategic organizational Development, infrastructure and Financial Performance: An Empirical Test, International Journal of Entrepreneurial Education, Vol 3, Issue 2 (2005), pp. 117-142.

[10] Flamholtz E and Y. Randle (1987) The Inner Game of Management, AMACOM.

[11] McGee, M. and E. Flamholtz (2005), The Transformation from Entrepreneurship to professional Management at Pardee Homes, International Journal of Entrepreneurial Education, Vol 3, Issue 2 pp. 185-204

[12] Nayar, M. and Flamholtz, E.(2005) The Transformation from Entrepreneurship to professional Management at Unitech Systems, International Journal of Entrepreneurial Education, Vol 3, Issue 2 pp. 169-184. 